\title{
Milk minerals modify the effect of fat intake on serum lipid profile: results from an animal and a human short-term study
}

\author{
Janne K. Lorenzen ${ }^{1}$, Søren K. Jensen ${ }^{2}$ and Arne Astrup ${ }^{1 *}$ \\ ${ }^{1}$ Department of Nutrition, Exercise and Sports (NEXS), Faculty of Sciences, University of Copenhagen, Rolighedsvej 30, \\ DK-1958 Frederiksberg C, Denmark \\ ${ }^{2}$ Department of Animal Science, Research Centre Foulum, Aarhus University, DK-8830 Tjele, Denmark \\ (Submitted 3 April 2013 - Final revision received 9 October 2013 - Accepted 16 October 2013 - First published online 25 November 2013)
}

\begin{abstract}
Despite a high content of saturated fat, evidence from observational studies indicates that the consumption of dairy products may have a neutral effect or may be inversely associated with the risk of CVD. We aimed to examine whether milk minerals modify the effect of saturated fat on serum lipid profile. We present data from two studies. Study I had a randomised, blinded, parallel design ( $n 24$ pigs) with a $10 \mathrm{~d}$ adaptation period during which a high-fat diet was fed to the pigs and a $14 \mathrm{~d}$ intervention period during which the same diet either enriched with milk minerals (MM group) or placebo (control group) was fed to the pigs. Study II had a randomised cross-over design ( $n 9$ men) where the subjects were fed either a high-fat diet enriched with milk minerals (MM period) or a regular diet (control period). In both the studies, blood variables were measured before and after the intervention and faecal and urine samples were collected at the end of the dietary periods. The increase in plasma total cholesterol and LDL-cholesterol concentrations but not in HDL-cholesterol concentration was markedly lowered by milk minerals in both the studies. In the animal study, baseline adjusted total cholesterol and LDL-cholesterol concentrations in the MM group were $11 \%(P=0.004)$ and $13 \%(P=0.03)$ lower compared with those in the control group after the intervention. Similarly in the human study, baseline adjusted total cholesterol and LDL-cholesterol concentrations were $6 \%$ $(P=0.002)$ and $9 \%(P=0.03)$ lower after the MM period compared with those in the control period. HDL-cholesterol concentration was not lowered by milk minerals. These short-term studies indicate that the addition of milk minerals to a high-fat diet to some extent attenuates the increase in total cholesterol and LDL-cholesterol concentrations, without affecting HDL-cholesterol concentration.
\end{abstract}

Key words: Dairy products: Cholesterol: Calcium: Faecal fat

Elevated LDL-cholesterol concentration is a major contributor to the development of CVD. On the contrary, high HDLcholesterol concentration has been shown to be associated with a decreased risk of $\mathrm{CVD}^{(1)}$. The relationship between LDL-cholesterol and CVD risk is continuous over a broad range of LDL-cholesterol concentrations; thus, the higher the LDL-cholesterol concentration, the greater the CVD risk $^{(2)}$. A reduction in LDL-cholesterol concentration by $1.0 \mathrm{mmol} / 1$ has been estimated to reduce all-cause mortality by $10 \%$ and deaths due to CVD by $20 \%$ with no significant effect on death due to cancer or other non-vascular causes ${ }^{(2)}$.

SFA, especially palmitic acid, are dietary components that are considered to be most responsible for increases in serum cholesterol concentrations, and as dairy products have a high content of SFA and cholesterol, it is a general perception that the intake of fatty dairy products is associated with an increased risk of $\mathrm{CVD}^{(3)}$. However, evidence from observational studies indicates that the consumption of milk or dairy products may have a neutral effect or may be inversely associated with the risk of developing $\mathrm{CVD}^{(4,5)}$. One of the components of dairy products shown to be associated with this reduced risk is $\mathrm{Ca}$. Dietary Ca intake has been observed to be inversely associated with total cholesterol and LDL-cholesterol concentrations ${ }^{(6)}$. In addition, studies have indicated that dairy products with a high content of $\mathrm{Ca}$, especially cheese, may not affect lipid profile adversely, as would otherwise be predicted from their fat content and composition (reviewed in Pfeuffer \& Schrezenmeir $^{(7)}$, Tholstrup ${ }^{(8)}$ and Nestel $\left.{ }^{(9)}\right)$. However, the results from intervention studies examining the effect of $\mathrm{Ca}$ (dairy or supplementary) on lipid profile are inconsistent ${ }^{(10-18)}$. In a short-term study, we have recently shown that the Ca content of dairy products may influence the effect of dairy fat on lipid profile by partly counteracting the raising effect of saturated fat on total cholesterol and LDL-cholesterol concentrations, without reducing HDL-cholesterol concentrations ${ }^{(19)}$. The study had a randomised cross-over design where subjects were given four diets with high or low content of dairy $\mathrm{Ca}$ and high or low content of dairy fat. A limitation of the study

Abbreviation: MM period/group, milk mineral period/group.

* Corresponding author: Professor A. Astrup, fax +45 3533 2483, email ast@life.ku.dk 
was diet composition. Although efforts were made to prepare diets similar in composition, differences in compositions arose due to the wide range of nutrients present in milk, thus possibly confounding the outcome. To examine this further, we carried out a substudy including an extra dietary period where the subjects were given the high-fat diet enriched with a milk mineral concentrate. Herein, the results of the present study are reported along with data from an animal study.

\section{Experimental work}

Study I - animal study

Study I had a randomised, blinded, parallel design with two intervention groups (milk mineral and control). The experimental period consisted of an adaptation period of $10 \mathrm{~d}$ during which the pigs were fed a high-fat diet followed by a $14 \mathrm{~d}$ intervention period during which the pigs were fed the high-fat diet enriched with milk minerals (MM group) or placebo (control group). Fasting blood samples were drawn before and after the intervention; body weight was measured at baseline and after the intervention period, and faecal and urine samples were collected during the last $48 \mathrm{~h}$ of the intervention period. The study complied with the Danish Ministry of Justice Law no. 1306 (23 November 2007) concerning experiments with animals and care of experimental animals and was under the supervision of the Danish Animal Experiments Inspectorate.

Animals. A total of twenty-four cross-bred barrows (initial weight $50-60 \mathrm{~kg}$ and age approximately 3 months, obtained from the Danish Institute of Agricultural Science swine herd, Foulum, Denmark) were divided into two weight-matched groups with twelve pigs in each group. The pigs were housed individually in pens. The study was carried out at the Department of Animal Science, Research Centre Foulum, Aarhus University, Tjele, Denmark.

Diet. The experimental period consisted of an adaptation period of $10 \mathrm{~d}$ during which the pigs were fed a high-fat diet followed by a $14 \mathrm{~d}$ intervention period during which the pigs were fed the high-fat diet enriched with a milk mineral concentrate (Capolac ${ }^{\circledR}$ MM0525; Arla Foods Ingredients Group P/S) or placebo (potato starch). Capolac ${ }^{\circledR}$ is a natural milk mineral concentrate used for Ca fortification of beverages, etc. It contains minimum $24 \% \mathrm{Ca}$ and $11 \%$ phosphate. The supplement was added to the diet before feeding it to the pigs. Before the experiment, the pigs were fed a standard diet with a fat content of $11 \mathrm{E} \%$ ( $3 \mathrm{E} \% \mathrm{SFA}$ ). The pigs had free access to water. They were fed $1.44 \mathrm{~kg}$ diet/d corresponding to $90 \%$ of their habitual intake to ensure that they ate all the diet ${ }^{(20)}$. The control diet had a Ca content corresponding to approximately $50 \%$ of the $\mathrm{Ca}$ recommendation for pigs ${ }^{(20)}$. The diet was given as two meals of equal amounts at 07.30 and 16.00 hours. The nutrient composition of the intervention diets is given in Table 1 (the diet fed during the adaptation period was similar to the control diet).

\section{Study II - human study}

Study II was a substudy of a previously reported study examining the effect of high and low $\mathrm{Ca}$ intake from dairy
Table 1. Nutrient composition of the two diets used in the animal study

\begin{tabular}{lcc}
\hline & MM group & Control group \\
\hline Protein (E\%) & 19 & 19 \\
Carbohydrate (E\%) & 50 & 50 \\
Fat (E\%) & 32 & 32 \\
SFA (E\%) & 11 & 11 \\
MUFA (E\%) & 13 & 13 \\
PUFA (E\%) & 9 & 9 \\
Ca (g/kg diet) & $10 \cdot 8$ & $5 \cdot 1$ \\
\hline MM, milk minerals; E\%, percentage of energy.
\end{tabular}

products $^{(19)}$. The study had a randomised (by draw), crossover design. The substudy included two intervention periods of $10 \mathrm{~d}$ with controlled intake of a high-fat diet. During the milk mineral period (MM period), the diet was enriched with a milk mineral concentrate as described below. Between the dietary periods, there was a washout period of at least 1 week during which the subjects consumed their habitual diets. The study was blinded to the subjects and the staff collecting, handling and analysing the blood, faecal and urine samples, but not to the staff preparing the diet. Data collected during the MM period reported herein have not been published previously.

Fasting blood samples (venous) were drawn in the morning of the first day of each dietary period and in the morning after the last day of each dietary period. Body weight was measured at baseline and before and after each dietary period. The subjects fasted on all the occasions. Body weight was measured in $\mathrm{kg}$ with one decimal using a Lindeltronic 8000 scale. Height was measured at baseline to the nearest centimetre using a Seca stadiometer.

All the faeces excreted were collected in preweighed containers during the last $5 \mathrm{~d}$ of each dietary period. In addition, the subjects completed a questionnaire on daily defecation frequency and stool consistency throughout each dietary period. The faecal samples were weighed and frozen at $-20^{\circ} \mathrm{C}$. Transit time was measured using non-absorbable, radio-opaque markers (Medifact). From the 4th to the 8th day of each dietary period, the subjects consumed a capsule containing twenty markers with breakfast. Different shaped markers were used each day. Transit time was measured as described elsewhere ${ }^{(21)}$ Retrieval of the markers consumed on days 5-7 was also used as a measurement for complete faeces collection. If the retrieval was above $70 \%$, the collection was assumed to be complete.

During the last $24 \mathrm{~h}$ of each dietary period, the subjects collected all the urine excreted. The urine volume was measured and samples were stored at $-20^{\circ} \mathrm{C}$ until further analyses.

Subjects. A total of fifteen male subjects were recruited by advertising in newspapers, on the Internet and at universities and student halls of residence in Copenhagen. The subjects were healthy, with a mean age of 32.8 (SEM 1.2) years and mean BMI of $28.1(\operatorname{sem} 0 \cdot 6) \mathrm{kg} / \mathrm{m}^{2}$. The exclusion criteria were smoking, lactose intolerance, infections or metabolic diseases, and use of dietary supplements. The study was carried out at the Department of Nutrition, Exercise and Sports (NEXS), Faculty of Sciences, University of Copenhagen, Frederiksberg, Denmark. The study was conducted according to the guidelines laid down in the Declaration of Helsinki, and 
all procedures involving human subjects were approved by the Municipal Ethical Committee of Copenhagen and Frederiksberg (KF 01-144/02). Written informed consent was obtained from all the subjects. The subjects were given 6000 DKK (Danish Krone, approximately 1000 \$) on completion of all the tests. The human study was registered at ClinicalTrails.gov (NCT00519909).

Diet. The nutrient composition of the two diets is given in Table 2. The computer database of foods of the National Food Agency of Denmark (Dankost 3000; National Food Agency of Denmark) was used to calculate the content of micro- and macronutrients, except when otherwise stated. The diets consisted of three different breakfast, lunch and dinner dishes and three different snacks, which were served on alternate days. The diets were prepared at the department according to each subject's individual energy requirement and adjusted to the nearest $1 \mathrm{MJ}$. The energy requirement of each subject was calculated as BMR $\times$ physical activity level. The BMR was estimated using the following equation ${ }^{(22)}$ :

$$
\mathrm{BMR}=0.102 \times \mathrm{FFM}+0 \cdot 024 \times \mathrm{FM}+0 \cdot 85 .
$$

Body composition was measured at baseline by bioelectrical impedance method, and fat-free mass (FFM) and fat mass (FM) were calculated (Animeter; Unitech). The basic physical activity level value of the subjects was set to 1.6$2 \cdot 0$, estimated on the basis of their main occupation ${ }^{(23)}$. If the subjects reported participating in sports in their spare time, their physical activity level value was increased according to the type of physical activity and the average hours spent weekly on the activity ${ }^{(24)}$. The mean energy requirement of the subjects who completed the study was $14 \mathrm{MJ} / \mathrm{d}$.

The subjects were given a protein drink with every main meal (to simulate milk). The protein drink given with the three main meals contained $45 \mathrm{E} \%$ protein (Lacprodan ${ }^{\circledR}$ DI-9224 and Miprodan ${ }^{\circledR}$ 30; Arla Foods Ingredients Group P/S) and $55 \mathrm{E} \%$ carbohydrate (Lactose Variolac ${ }^{\circledR}$ 992; Arla Foods Ingredients Group $\mathrm{P} / \mathrm{S}$ ). In addition, they were given a chocolate drink containing the protein drink, cream and chocolate power to consume with the snack. Similar to the rest of the diet, the amount of protein/chocolate drink was adjusted according to the energy requirement of the subjects. During the MM period, all the drinks were enriched with Capolac ${ }^{\circledR}$ MM0525 (Arla Foods Ingredients Group P/S). The total nutrient composition

Table 2. Nutrient composition of the two diets used in the human study *

\begin{tabular}{lcc}
\hline & MM period & Control period \\
\hline Protein (E\%) & 15 & 15 \\
Carbohydrate (E\%) & 36 & 36 \\
Fat (E\%) & 50 & 50 \\
SFA (E\%) & 26 & 26 \\
MUFA (E\%) & 15 & 15 \\
PUFA (E\%) & 3 & 3 \\
Ca (mg/10 MJ) & 1990 & 470
\end{tabular}

MM, milk minerals; $E \%$, percentage of energy.

*Each diet consisted of three different breakfast, lunch and dinner dishes and three different snacks, which were served on alternate days. of the diets including that of the drinks is given in Table 2. On weekdays, the subjects consumed breakfast at the department, whereas lunch, snacks and dinner were given to them to be eaten at home. All the meals for the weekends were supplied to the subjects to be consumed at home. The subjects were instructed to strictly adhere to the diet plan and not to mix the different meals and to report any deviation from the diet plan. In addition to the meals, the subjects were given water with a low content of $\mathrm{Ca}(12 \mathrm{mg} / \mathrm{l})$, which they were allowed to drink ad libitum. They were allowed to make tea and coffee with this water. The subjects were instructed to register their intake, and no significant differences in water intake between the dietary periods were found (data not shown).

\section{Laboratory analyses}

Collection of blood samples. Blood samples for plasma analyses were collected in tubes containing EDTA and placed on ice immediately. Blood samples for serum analyses were collected in serum tubes and kept at room temperature for $30 \mathrm{~min}$ to coagulate. All the samples were centrifuged at $2800 \mathrm{~g}$ for $15 \mathrm{~min}$ at $4^{\circ} \mathrm{C}$ and stored at $-20^{\circ} \mathrm{C}$ until later analysis (samples for LDL analysis were stored at $-80^{\circ} \mathrm{C}$ ).

Measurement of serum concentrations of total cholesterol, HDL-cholesterol, NEFA and TAG. Total cholesterol concentration was measured by an enzymatic photometric test (CHOD-PAP) using a Pentra 400 analyser (HORIBA ABX). The $\mathrm{CV}_{\text {intra }}$ and $\mathrm{CV}_{\text {inter }}$ were 0.9 and $1.6 \%$, respectively. HDLcholesterol concentration was measured by an enzymatic colorimetric test using a Pentra 400 analyser. The $\mathrm{CV}_{\text {intra }}$ and $\mathrm{CV}_{\text {inter }}$ were 1.2 and $4.0 \%$, respectively. LDL-cholesterol concentration was measured by an enzymatic colorimetric test using a Pentra 400 analyser. The $\mathrm{CV}_{\text {intra }}$ and $\mathrm{CV}_{\text {inter }}$ were 1.3 and $2.7 \%$, respectively. NEFA concentration was determined by an enzymatic colorimetric method using a Pentra 400 analyser. The $\mathrm{CV}_{\text {intra }}$ and $\mathrm{CV}_{\text {inter }}$ were 1.7 and $5.1 \%$, respectively. TAG concentration was measured by an enzymatic photometric test using a Pentra 400 analyser. The $\mathrm{CV}_{\text {intra }}$ and $\mathrm{CV}_{\text {inter }}$ were 2.6 and $3 \cdot 2 \%$, respectively. Insulin concentration was determined by a chemiluminescence immunometric assay using an Immulite 1000 analyser (DPC; Diagnostic Products Corporation). The $\mathrm{CV}_{\text {intra }}$ and $\mathrm{CV}_{\text {inter }}$ were $2 \cdot 7$ and $7 \cdot 4 \%$, respectively.

Measurement of plasma concentration of glucose. Glucose concentration was measured by an enzymatic endpoint method (hexokinase) using a Pentra 400 analyser. The $\mathrm{CV}_{\text {intra }}$ and $\mathrm{CV}_{\text {inter }}$ were 0.7 and $2.5 \%$, respectively.

Analysis of faecal samples. Before analysis, the faecal samples were freeze-dried and homogenised, and samples collected during the same dietary period were pooled. Faecal energy was determined using a bomb calorimeter (Ika-calorimeter system C4000; Heitersheim). Before the measurement of total fat content, the samples were hydrolysed with $3 \mathrm{M}-\mathrm{HCl}$. In study I, total fat content was measured using a Soxhlet method (ANKOM Technology) with modifications. In study II, total fat content was measured by acidic Bligh and Dyer extraction $^{(25)}$. Bile acids in the faecal samples (only in study II) were quantified by reversed-phase HPLC with pulsed amperometric detection as described previously ${ }^{(26,27)}$. The freeze-dried 
samples ( $1 \mathrm{~g}$ ) were diluted 50-fold in a mixture containing $20 \%$ acetonitrile, $10 \% \mathrm{NaOH}$ and $70 \%$ water. Ursodeoxycholate (Sigma) was added to the mixture as an internal standard at a final concentration of $40 \mathrm{mmol} / \mathrm{l}$. The mixture was mixed using a Shaker VXR vibrax (IKA-Werke) at $1500 \mathrm{rpm}$ for $30 \mathrm{~s}$ and subsequently centrifuged at $5000 \mathrm{~g}$ for $10 \mathrm{~min}$. The supernatant was passed through a nylon syringe filter membrane (Cameo $17 \mathrm{~N}$ 227DDR02T17NB) before injection onto the HPLC column. Fat and bile acid concentrations were measured only in study II.

$\mathrm{Ca}$ concentration was measured by atomic absorption spectrophotometry using a PYE UNICAM SP9 atomic absorption spectrophotometer (Philips Electron Optics). Before analysis, the samples were subjected to dry ashing at $525^{\circ} \mathrm{C}$ for $6 \mathrm{~h}$, and the ashes were dissolved in acid $(6.5 \%$ $\mathrm{HNO}_{3}$ ). The solution was diluted with a lanthanum chloride solution before measuring $\mathrm{Ca}$ concentration.

Analysis of urine samples. Urinary Ca concentration was measured using atomic absorption on a SpectrAA-200 instrument (Varian). The $\mathrm{CV}_{\text {intra }}$ and $\mathrm{CV}_{\text {inter }}$ were $2 \cdot 1$ and $2.9 \%$, respectively.

\section{Statistical analyses}

Data are expressed as means with their standard errors unless otherwise stated.

For study II (human study), a power calculation was performed for the main study ${ }^{(19)}$. The calculation, which was based on studies previously carried out at our department, showed that a study group of twelve subjects would give us sufficient power $(85 \%)$ to detect a difference in faecal fat excretion of at least $4 \mathrm{~g} / \mathrm{d}$. By calculating with a dropout rate of $20 \%$, we included fifteen subjects in the study.

ANCOVA were used to examine the effect of milk minerals on blood variables. ANCOVA were carried out in PROC MIXED. Values obtained before the dietary period were included as a covariate in all the analyses. As study II (human study) had a cross-over design, subjects were included as a random effect. Least-squares means were used to estimate the adjusted means. Differences from baseline to the period after intervention within the group/period were examined using a paired $t$ test. Differences in faecal and urinary variables were analysed by $t$ test in study I (animal study) and by one-way ANOVA with subjects included as a random effect in study II (human study). Correlation between two parameters was examined by linear regression. Adjusted $\mathrm{R}^{2}$ was used to assess how well the linear regression model predicted the dependent variable. Model control for all the analyses was performed, and data were transformed and outliers excluded before analyses, if necessary. All the statistical analyses were carried out using the Statistical Analysis Package, SAS ${ }^{\odot}$ version 9.1 (SAS Institute). The level of significance was set at $P<0 \cdot 05$.

\section{Results}

Study I - animal study

None of the pigs exhibited any side effects during the study. There was no significant difference in body weight at baseline (MM group 54.5 (SEM 0.8) kg $v$. control group 54.3 (SEM 0.9) kg; $P=0.9223$ ) or after the intervention period (MM group 73.0 (SEM 0.6 ) $\mathrm{kg} v$. control group 73.4 (sem 0.6) kg; $P=0.5621$ adjusted for baseline body weight).

Blood parameters. An outlier was identified in the control group. During the intervention period, in which this pig was given the same diet fed during the adaptation period, an unexplainable large decrease in total cholesterol concentration was observed. Model control, which was performed before the statistical analyses, revealed this value to be a significant outlier. A similar decrease was observed in LDL-cholesterol and HDL-cholesterol concentrations, and values of all the blood parameters of this pig were excluded from the data analyses.

Total cholesterol, LDL-cholesterol, and HDL-cholesterol concentrations and HDL-cholesterol:LDL-cholesterol and total cholesterol:HDL-cholesterol of the two groups before and after the intervention are given in Table 3. In the control group, there was a significant increase in both total cholesterol $(0.44 \quad(\mathrm{SEM} \quad 0 \cdot 11) \mathrm{mmol} / \mathrm{l} ; \quad P=0.003)$ and LDL-cholesterol (0.31 (sem 0.09$) \mathrm{mmol} / \mathrm{l} ; \quad P=0.006$ ) concentrations from baseline to the period after intervention. However, when milk minerals were added to the diet, the increase in both total cholesterol (0.12 (SEM 0.09) $\mathrm{mmol} / \mathrm{l}$; $P=0.22)$ and LDL-cholesterol (0.05 (sEM 0.06$) \mathrm{mmol} / \mathrm{l}$; $P=0.39)$ concentrations was markedly lower and no longer significant.

ANCOVA indicated a significant effect of the intervention on total cholesterol $(P=0.004)$ and LDL-cholesterol $(P=0.03)$ concentrations, when adjusting for baseline concentration. Baseline adjusted total cholesterol concentration in the MM group was $11 \%$ lower after the intervention compared with that in the control group (adjusted mean: MM group $3.02 \mathrm{mmol} / \mathrm{l} v$. control group $3.38 \mathrm{mmol} / \mathrm{l} ; P=0 \cdot 004)$. Similarly, baseline adjusted LDL-cholesterol concentration in the MM group was 13\% lower after the intervention compared with that in the control group (adjusted mean: MM group $1.54 \mathrm{mmol} / 1 \quad v$. control group $1.78 \mathrm{mmol} / 1 ; \quad P=0.03)$. There was no significant difference in HDL-cholesterol concentration, total cholesterol:HDL-cholesterol or HDLcholesterol:LDL-cholesterol.

Faecal and urinary excretion. Faecal fat, energy and Ca excretion values as well as urinary $\mathrm{Ca}$ excretion value are given in Table 4. As expected, Ca excretion was significantly higher in the MM group than in the control group. In addition, faecal fat excretion in the MM group was 31\% higher compared with that in the control group $(P=0 \cdot 04)$. There was a significant correlation between faecal fat and $\mathrm{Ca}$ excretion $(P<0 \cdot 0001)$ :

$$
\text { Faecal fat }(\mathrm{g})=19 \cdot 2+0 \cdot 0041 \times \text { faecal Ca }(\mathrm{mg}) \text {. }
$$

Faecal Ca excretion explained $65 \%$ of faecal fat excretion $\left(R^{2}\right.$ 0.6488; $\left.P<0.0001\right)$. Although faecal energy excretion was somewhat higher in the MM group than in the control group, there was no significant difference between the two groups $(P=0 \cdot 4844)$. 
Table 3. Concentrations of blood parameters before and after the intervention in the animal study (study I) (Mean values with their standard errors)

\begin{tabular}{|c|c|c|c|c|c|}
\hline & \multicolumn{2}{|c|}{ MM group } & \multicolumn{2}{|c|}{ Control group } & \multirow[b]{2}{*}{ Effect of intervention $(P) \dagger$} \\
\hline & Mean & SEM & Mean & SEM & \\
\hline Total cholesterol $(\mathrm{mmol} / \mathrm{l}) \ddagger$ & & & & & 0.004 \\
\hline Before & 3.06 & 0.19 & 2.97 & $0 \cdot 16$ & \\
\hline After & $3 \cdot 18$ & 0.22 & $3.40^{*}$ & $0 \cdot 15$ & \\
\hline LDL-cholesterol $(\mathrm{mmol} / \mathrm{l}) \S$ & & & & & 0.03 \\
\hline Before & 1.63 & 0.12 & 1.38 & 0.09 & \\
\hline After & 1.68 & 0.14 & $1.69^{*}$ & 0.09 & \\
\hline \multicolumn{6}{|l|}{ HDL-cholesterol (mmol/l) } \\
\hline Before & $1 \cdot 18$ & 0.07 & 1.37 & 0.09 & 0.67 \\
\hline After & 1.14 & 0.08 & 1.31 & $0 \cdot 10$ & \\
\hline $\mathrm{TAG}(\mathrm{mmol} / \mathrm{l})$ & & & & & 0.34 \\
\hline Before & 0.39 & 0.04 & 0.30 & 0.07 & \\
\hline After & 0.38 & 0.04 & 0.31 & 0.03 & \\
\hline HDL-cholesterol:LDL-cholesterol & & & & & 0.70 \\
\hline Before & 0.73 & 0.04 & 1.01 & 0.07 & \\
\hline After & 0.70 & 0.05 & $0.80^{*}$ & 0.07 & \\
\hline Total cholesterol:HDL-cholesterol§̧ & & & & & 0.70 \\
\hline Before & 2.63 & 0.10 & 2.21 & 0.08 & \\
\hline After & $2 \cdot 88$ & 0.22 & $2 \cdot 71^{*}$ & 0.20 & \\
\hline
\end{tabular}

MM, milk minerals.

${ }^{*}$ Mean value was significantly different from that measured before the dietary period $(P<0.05$; paired $t$ test $)$

t ANCOVA, adjusted for the concentration measured before each dietary period.

$\ddagger$ Inverse-transformed before the statistical analyses.

$\S$ Log-transformed before the statistical analyses.

\section{Study II - human study}

Of the fifteen subjects, nine completed the study. Reasons for not completing the study were moving home (one subject) and problems with compliance to the protocol (five subjects). Only data collected from the subjects completing the study were included in the data analyses. The habitual $\mathrm{Ca}$ intake of the subjects was 1223 (SEM 96) $\mathrm{mg} / \mathrm{d}$.

Blood parameters. Total cholesterol, LDL-cholesterol, HDLcholesterol, and TAG concentrations and HDL-cholesterol: LDL-cholesterol and total cholesterol:HDL-cholesterol before and after each dietary period are given in Table 5 .

In agreement with data obtained in study I, the increase in total cholesterol and LDL-cholesterol concentrations was partly counteracted by the addition of milk minerals to the diet. In the control period, there was a significant increase in both total cholesterol $(0.59$ (SEM 0.10$) \mathrm{mmol} / 1 ; P=0.0004)$ and LDL-cholesterol (0.69 (sem $0 \cdot 11) \mathrm{mmol} / \mathrm{l} ; \quad P=0.0003)$ concentrations due to the high-fat diet. However, when milk minerals were added to the diet, the increase in both total cholesterol (0.28 (SEM 0.12$) \mathrm{mmol} / \mathrm{l} ; \quad P=0.05)$ and LDLcholesterol $(0.41$ (SEM 0.12$) \mathrm{mmol} / 1 ; P=0.01)$ concentrations was markedly lower.

ANCOVA indicated a significant effect of the intervention on total cholesterol $(P=0.002)$ and LDL-cholesterol $(P=0.03)$ concentrations, when adjusting for baseline concentration. Total cholesterol concentration was $6 \%$ lower after the MM period compared with that in the control period (adjusted mean: MM period $5.26 \mathrm{mmol} / 1 \quad v$. control period $5.62 \mathrm{mmol} / 1$; $P=0 \cdot 002$ ). Similarly, baseline adjusted LDL-cholesterol concentration was $9 \%$ lower after the MM period compared with that in the control period (adjusted mean: MM period $3.34 \mathrm{mmol} / 1 \quad v$. control period $3.66 \mathrm{mmol} / 1 ; \quad P=0.03)$. There was no significant difference in HDL-cholesterol

Table 4. Faecal and urinary parameters in the animal study (study I) (Mean values with their standard errors)

\begin{tabular}{|c|c|c|c|c|c|}
\hline & \multicolumn{2}{|c|}{ MM group } & \multicolumn{2}{|c|}{ Control group } & \multirow[b]{2}{*}{ Effect of intervention $(P)^{*}$} \\
\hline & Mean & SEM & Mean & SEM & \\
\hline Total fat excretion (g/d) & $50 \cdot 2$ & $3 \cdot 3$ & 38.4 & $4 \cdot 4$ & 0.04 \\
\hline Energy excretion (kJ/d) & 3873 & 264 & 3551 & 368 & 0.48 \\
\hline Faecal wet weight (g/d) & 542 & 47 & 503.5 & 55 & 0.60 \\
\hline \multicolumn{6}{|l|}{ Ca excretion } \\
\hline Urinary Ca excretion $(\mathrm{mg} / \mathrm{d}) \dagger$ & 315 & 51 & 189 & 46 & 0.046 \\
\hline Faecal Ca excretion (mg/d) & 8398 & 539 & 3835 & 429 & $<0.0001$ \\
\hline Total Ca excretion (mg/d) & 8712 & 545 & 4024 & 431 & $<0.0001$ \\
\hline
\end{tabular}

MM, milk minerals.

${ }^{*} t$ test.

†Data were log-transformed before the statistical analyses. 
Table 5. Concentrations of blood parameters before and after the intervention in the human study (study II) (Mean values with their standard errors)

\begin{tabular}{|c|c|c|c|c|c|}
\hline & \multicolumn{2}{|c|}{ MM period } & \multicolumn{2}{|c|}{ Control period } & \multirow[b]{2}{*}{ Effect of intervention $(P) \ddagger$} \\
\hline & Mean & SEM & Mean & SEM & \\
\hline \multicolumn{5}{|l|}{ Total cholesterol (mmol/l) } & 0.002 \\
\hline Before & 4.92 & 0.20 & 5.09 & 0.24 & \\
\hline After & $5 \cdot 20 \dagger$ & 0.15 & $5 \cdot 68^{*}$ & 0.21 & \\
\hline \multicolumn{5}{|l|}{ LDL-cholesterol (mmol/l) } & 0.03 \\
\hline Before & 2.86 & 0.17 & 3.04 & 0.17 & \\
\hline After & $3 \cdot 27$ & 0.16 & $3.73^{*}$ & 0.21 & \\
\hline \multicolumn{5}{|l|}{ HDL-cholesterol $(\mathrm{mmol} / \mathrm{l}) \S$} & 0.91 \\
\hline Before & $1 \cdot 20$ & 0.10 & $1 \cdot 14$ & 0.09 & \\
\hline After & 1.26 & 0.09 & 1.21 & 0.06 & \\
\hline \multicolumn{6}{|l|}{ TAG $(\mathrm{mmol} / \mathrm{l})$} \\
\hline Before & 1.65 & 0.28 & 1.56 & 0.34 & \\
\hline After & 1.03 & 0.11 & $1 \cdot 13$ & $0 \cdot 16$ & \\
\hline \multicolumn{6}{|l|}{ HDL-cholesterol:LDL-cholesterol§ } \\
\hline Before & 0.44 & 0.05 & 0.39 & 0.04 & 0.39 \\
\hline After & 0.40 & 0.04 & $0.34^{*}$ & 0.03 & \\
\hline \multicolumn{5}{|l|}{ Total cholesterol:HDL-cholesterol\| } & 0.17 \\
\hline Before & $4 \cdot 30$ & 0.35 & 4.63 & 0.38 & \\
\hline After & 4.28 & 0.30 & 4.77 & 0.30 & \\
\hline
\end{tabular}

MM, milk minerals.

${ }^{*}$ Mean value was significantly different from that measured before the dietary period $(P<0.05$; paired $t$ test) $\dagger P=0.05$.

$\ddagger$ ANCOVA, adjusted for the concentration measured before each dietary period.

$\S$ Log-transformed before the statistical analyses.

|| Square-transformed before the statistical analyses.

concentration, total cholesterol:HDL-cholesterol or HDLcholesterol:LDL-cholesterol.

Faecal and urinary excretion. Faeces collection in one subject during the control period was judged incomplete due to a low recovery of transit markers $(<70 \%)$, and data of this subject were therefore excluded.

Faecal fat, total bile acid, energy and Ca excretion values and urinary $\mathrm{Ca}$ excretion value are given in Table 6. Faecal energy $(P<0 \cdot 0001)$ and total $\mathrm{Ca}(P<0 \cdot 0001)$ excretion was significantly higher during the MM period than during the control period. In addition, faecal fat excretion was 39\% higher during the MM period compared with that during the control period $(P=0.0004)$. Similar to that observed in study I, there was a significant correlation between faecal fat and $\mathrm{Ca}$ excretion $(P=0.002)$ :

$\log 10($ faecal fat $(\mathrm{g}))=0 \cdot 7624+0.0001 \times$ faecal Ca $(\mathrm{mg})$.

Faecal Ca excretion explained $43 \%$ of faecal fat excretion $\left(R^{2} 0.4345 ; P=0.002\right)$. There was a trend for higher faecal energy excretion during the MM period than during the control period $(P=0 \cdot 06)$. There was no significant difference in

Table 6. Faecal and urinary parameters in the two dietary periods in the human study (study II)

(Mean values with their standard errors)

\begin{tabular}{|c|c|c|c|c|c|}
\hline & \multicolumn{2}{|c|}{ MM group } & \multicolumn{2}{|c|}{ Control period } & \multirow[b]{2}{*}{ Effect of intervention $(P)^{\star}$} \\
\hline & Mean & SEM & Mean & SEM & \\
\hline Total fat excretion $(\mathrm{g} / \mathrm{d}) \dagger$ & $9 \cdot 2$ & 0.7 & $6 \cdot 6$ & 0.5 & 0.0004 \\
\hline Energy excretion $(\mathrm{kJ} / \mathrm{d}) \dagger$ & 774 & 57 & 650 & 64 & 0.057 \\
\hline \multicolumn{6}{|l|}{ Faecal wet weight } \\
\hline \multicolumn{6}{|l|}{ Bile acid excretion } \\
\hline Total bile acid excretion $(\mu \mathrm{mol} / \mathrm{d}) \dagger$ & 331 & 54 & 274 & 54 & 0.27 \\
\hline Glycine-conjugated bile acids ( $\mathrm{mmol} / \mathrm{d}) \dagger$ & 105 & 21 & 67 & 19 & 0.02 \\
\hline Taurine-conjugated bile acids (mmol/d) & 49 & 10 & 50 & 11 & 0.96 \\
\hline Total conjugated bile acids $(\mathrm{mmol} / \mathrm{d}) \dagger$ & 154 & 23 & 117 & 25 & 0.09 \\
\hline Total deconjugated bile acids (mmol/d) & 129 & 26 & 134 & 29 & 0.92 \\
\hline \multicolumn{6}{|l|}{ Ca excretion } \\
\hline Faecal Ca excretion $(\mathrm{mg} / \mathrm{d})$ & 1948 & 184 & 549 & 34 & $<0.0001$ \\
\hline Urinary Ca excretion (mg/d) & 164 & 22 & 120 & 17 & 0.12 \\
\hline Total Ca excretion $(\mathrm{mg} / \mathrm{d})$ & 2112 & 168 & 667 & 25 & $<0.0001$ \\
\hline
\end{tabular}

MM, milk minerals.

${ }^{\star} t$ test.

† Log-transformed before the statistical analyses. 
total bile acid excretion between the two periods, but excretion of glycine-conjugated bile acids was significantly higher during the MM period than during the control period $(P=0 \cdot 02)$.

\section{Discussion}

The present study examined the short-term effects of milk minerals on blood lipid profile and faecal fat and energy excretion. The major finding is that milk minerals partly attenuate the increase in total cholesterol and LDL-cholesterol concentrations caused by the high intake of saturated fat, without affecting the increase in HDL-cholesterol concentration. The underlying mechanism is probably, at least in part, increased faecal excretion of fatty acids and possibly also of other hydrophobic components including bile acids and cholesterol. However, an unidentified mechanism seems to be involved as well.

Elevated LDL-cholesterol concentration is a major contributor to the development of CVD, and it is well accepted that SFA increase LDL-cholesterol concentration ${ }^{(1,28)}$. However, data on the effect of dairy products, which have a high content of SFA, are conflicting ${ }^{(7-9)}$. Recently, the association between milk/dairy product consumption and the risk of CVD and total mortality has been addressed in two meta-analyses, and both have shown a neutral or small beneficial effect of milk/dairy product consumption ${ }^{(4,5)}$. Elwood et al. ${ }^{(4)}$ found it reasonable to conclude that there is no evidence that dairy foods as a total group are associated with harm to health, in terms of death, heart disease, stroke or diabetes, but that they are probably beneficial in relation to these disease outcomes. We have recently shown that the intake of dairy $\mathrm{Ca}$, mainly as milk, may partly counteract the raising effect of saturated fat on total and LDL-cholesterol concentrations, without reducing HDL-cholesterol concentration ${ }^{(19)}$. The primary aim of the present study was to examine whether similar effects could be observed with milk mineral concentrates. In both the studies reported herein, the milk mineral concentrate was found to partly counteract the increase in LDL-cholesterol concentration caused by the high-fat diet. Similar effects were found on total cholesterol concentration, whereas no effect was observed on HDL-cholesterol concentration. Ca, which is the dominating mineral among the milk minerals, has previously been found to have a cholesterol-reducing effect per se ${ }^{(12,13)}$. Shahkhalili et al. ${ }^{(13)}$ showed, in a crossover study, that supplementation of chocolate with $0.9 \mathrm{~W} \%$ $\mathrm{Ca}$ (as calcium carbonate), as part of a diet providing $39 \mathrm{E} \%$ fat, resulted in a significantly higher decrease in LDLcholesterol concentration compared with a similar diet with regular chocolate $(0.43 \quad(\mathrm{SEM} \quad 0.39) \mathrm{mmol} / \mathrm{l} \quad v$. $0.01 \quad$ (SEM $0.25) \mathrm{mmol} / \mathrm{l} ; \quad P<0.02)$. In a randomised placebo-controlled study on Ca supplementation (1000 mg Ca as calcium citrate; $n 223$ healthy postmenopausal women), Reid et al. ${ }^{(15)}$ found that 1 -year supplementation led to a $7 \%$ increase in HDLcholesterol concentration and a trend towards a decrease in LDL-cholesterol concentration $(6 \% ; P=0.09)$. The interference is most probably due to the formation of insoluble Ca-fatty acid soaps and/or the formation of hydrophobic aggregations with phosphorus and bile acids and with other hydrophobic components, including fatty acids ${ }^{(29-32)}$. Some studies indicate that Ca mostly interferes with $\mathrm{SFA}^{(12-13,33)}$, but not all ${ }^{(34)}$. In both study I and study II, milk minerals were found to increase faecal fat excretion, and in study II, there was also an increased excretion of glycine-conjugated bile acids but not of taurine-conjugated bile acids, which is in agreement with previous findings ${ }^{(31)}$. However, the increased faecal fat excretion observed in the present study can only partly explain the cholesterol-decreasing effect of milk minerals observed in the present study. Therefore, it is most likely that another yet unidentified mechanism is involved. In addition to $\mathrm{Ca}$, the milk mineral concentrate contained other minerals that may affect the blood lipid profile including phosphate and $\mathrm{Mg}$. As has been described above, it has been suggested that phosphate is involved in the binding and precipitation of bile acids and other hydrophobic components, including fatty acids. The beneficial effects of calcium phosphate on total cholesterol and LDL-cholesterol have been reported by Ditscheid et $a l{ }^{(35)}$. Mg supplementation has been shown to have a beneficial effect on blood lipid profile in patients with type 2 diabetes, but mostly due to an increase in HDL-cholesterol concentration ${ }^{(36)}$.

A reduction in LDL-cholesterol concentration has been shown to markedly lower the risk of CVD. Based on a metaanalysis including data obtained from approximately 170000 subjects participating in a randomised trial with statins, the Cholesterol Treatment Trialists' Collaboration concluded in 2012 that a reduction in LDL-cholesterol concentration by $1.0 \mathrm{mmol} / \mathrm{l}$ can reduce the risk of major vascular events by $21 \%{ }^{(2)}$. The proportional reductions in major vascular events per $1.0 \mathrm{mmol} / 1 \mathrm{LDL}$-cholesterol concentration reduction for subjects who had a low risk of developing major vascular events were found to be at least as large as those for the other participants. The effect was similar in subjects with LDL-cholesterol concentration $<3.5 \mathrm{mmol} / 1$ and in those with LDL concentration $\geq 3.5 \mathrm{mmol} / 1$ at baseline. HDL functions in the reversal of cholesterol transport, by mediating cholesterol efflux from peripheral tissues, hepatocytes and macrophages, and in contrast to LDL-cholesterol, HDLcholesterol has been shown to be inversely associated with CVD risk ${ }^{(1)}$. An increment of $1 \mathrm{mg} / \mathrm{dl} \quad(0.026 \mathrm{mmol} / \mathrm{l})$ HDL-cholesterol concentration has been shown to be associated with a $2-3 \%$ decrease in the risk of $\mathrm{CVD}^{(37)}$. The intake of SFA has been shown to increase HDL-cholesterol concentration as well ${ }^{(28)}$. Such an increase was also observed in the present study and this was not affected by the addition of milk minerals.

In contrast to the beneficial effect of dairy products on CVD, Ca supplements (without co-administered vitamin D) have recently been shown to be associated with an increased risk of myocardial infarction ${ }^{(38,39)}$. Li et al. ${ }^{(39)}$ found that a moderately higher dietary or dairy $\mathrm{Ca}$ intake was associated with a lower myocardial infarction risk and that $\mathrm{Ca}$ supplement intake was associated with an increased myocardial infarction risk. Bolland et al. ${ }^{(38)}$ suggested that the increased risk is due to an increase in serum Ca concentration caused by the supplements and that, as it has been shown that $\mathrm{Ca}$ from dairy 
products has a much smaller effect on serum Ca concentration than Ca supplements, this could explain why supplementary $\mathrm{Ca}$ but not dairy $\mathrm{Ca}$ increased the risk of myocardial infarction. We did not measure serum Ca concentrations in the present study, but recommend that future studies address this topic as well.

Both study I and study II have some limitations. First, both studies were short-term studies, and we cannot exclude the possibility that an adaptation to a long-term high intake of milk minerals may occur, which could reduce the effect on cholesterol concentration. Further long-term studies are necessary to establish this. It is also important to emphasise that our primary aim was to examine whether milk minerals could interfere with the lipid-raising effect of saturated fat, and therefore the diet used in study II was designed to have a high content of fat. The diet contained $50 \mathrm{E} \%$ fat. In Denmark, the average fat intake among adults is $33 \mathrm{E} \%$ and the average saturated fat intake is $14 \mathrm{E} \%{ }^{(40)}$. In study $\mathrm{I}$, the pigs were given an experimental diet with a fat content of $32 \mathrm{E} \%$ ( $11 \mathrm{E} \% \mathrm{SFA})$, whereas the standard diet that they were fed before the study had a fat content of $11 \mathrm{E} \%$ fat $(3 \mathrm{E} \%$ SFA). Furthermore in the animal study, the main source of fat in the diet was not dairy fat but animal fat. However, this indicates that the beneficial effect of milk minerals is not specific to dairy fat and that the addition of milk minerals to other high-fat products may be beneficial, which is in agreement with the findings of previous studies on $\mathrm{Ca}$ enrichment ${ }^{(13)}$. To fully understand the effects of milk minerals on blood lipid profile, larger studies in free-living subjects are necessary.

The findings of the present study indicate that the addition of milk minerals to a diet rich in fat may partly counteract the raising effect of saturated fat on total cholesterol and LDLcholesterol concentrations, without reducing HDL-cholesterol concentration. The effect can partly be explained by an increased excretion of faecal fat, but another yet unidentified mechanism must be involved as well. These findings may contribute to explain why dairy products high in saturated fat and $\mathrm{Ca}$ are not associated with an increased risk of CVD.

\section{Supplementary material}

To view supplementary material for this article, please visit http://dx.doi.org/1.1017/S0007114513003826

\section{Acknowledgements}

The authors are grateful to the laboratory and kitchen staff, especially Elisabet Steinthorsdottir, Charlotte Kostecki and Yvonne Rasmussen, for their assistance with the human study and to Dr Henry Jørgensen and Hugo Christensen for their assistance with the animal study.

The study was financed by The Danish Dairy Board, Aarhus, Denmark, and The Directorate for Food, Fisheries and Agri Business, the Danish Ministry of Food, Agriculture and Fisheries, Copenhagen, Denmark, Arla Foods amba and Arla Foods Ingredients. The human study was part of a $\mathrm{PhD}$ project financed by FOOD Graduate School, Arla Foods amba and Faculty of Life Science, University of Copenhagen. Neither of the funders had a role in the design and analysis of the study or in the writing of this article.

The authors' contributions are as follows: J. K. L. and A. A. designed the study; J. K. L. conducted the human study and analysed the data; S. K. J. conducted the animal study. All authors participated in the discussion of the results and preparation of the manuscript.

A. A. is currently a member of advisory boards for the following bodies with interests related to the dairy industry: Global Dairy Platform, USA; Danone A/S Scandinavia, Sweden; Kraft Foods Worldwide Health \& Wellness Advisory Council, USA. In the past, he has received funding from Arla Foods A/S and The Danish Dairy Association and from international dairy interests contributing to a collaborative grant coordinated by Global Dairy Platform. J. K. L. has been involved in several of these projects. J. K. L. has also received funding from Arla Foods A/S and The Danish Dairy Association.

\section{References}

1. Prospective Studies Collaboration (2007) Blood cholesterol and vascular mortality by age, sex, and blood pressure: a meta-analysis of individual data from 61 prospective studies with 55,000 vascular deaths. Lancet 370, 1829-1839.

2. Cholesterol Treatment Trialists' (CTT) Collaborators (2012) The effects of lowering LDL cholesterol with statin therapy in people at low risk of vascular disease: meta-analysis of individual data from 27 randomised trials. Lancet $\mathbf{3 8 0}$, $581-590$

3. Grundy SM \& Denke MA (1990) Dietary influences on serum lipids and lipoproteins. J Lipid Res 31, 1149-1172.

4. Elwood PC, Pickering JE, Givens DI, et al. (2010) The consumption of milk and dairy foods and the incidence of vascular disease and diabetes: an overview of the evidence. Lipids 45, 925-939.

5. Soedamah-Muthu SS, Ding EL, Al-Delaimy WK, et al. (2011) Milk and dairy consumption and incidence of cardiovascular diseases and all-cause mortality: dose-response metaanalysis of prospective cohort studies. Am J Clin Nutr 93, $158-171$.

6. Jacqmain M, Doucet E, Després JP, et al. (2003) Calcium intake, body composition, and lipoprotein-lipid concentrations in adults. Am J Clin Nutr 77, 1448-1452.

7. Pfeuffer M \& Schrezenmeir J (2000) Bioactive substances in milk with properties decreasing risk of cardiovascular diseases. Br J Nutr 84, Suppl. 1, S155-S159.

8. Tholstrup T (2006) Dairy products and cardiovascular disease. Curr Opin Lipidol 17, 1-10.

9. Nestel PJ (2008) Effects of dairy fats within different foods on plasma lipids. J Am Coll Nutr 27, 735S-740S.

10. Zemel MB, Thompson W, Milstead A, et al. (2004) Calcium and dairy acceleration of weight and fat loss during energy restriction in obese adults. Obes Res 12, 582-590.

11. Thompson WG, Rostad Holdman N, Janzow DJ, et al. (2005) Effect of energy-reduced diets high in dairy products and fiber on weight loss in obese adults. Obes Res $\mathbf{1 3}$ 1344-1353.

12. Denke MA, Fox MM \& Schulte MC (1993) Short-term dietary calcium fortification increases fecal saturated fat content and reduces serum lipids in men. $J$ Nutr 123, 1047-1053

13. Shahkhalili Y, Murset C, Meirim I, et al. (2001) Calcium supplementation of chocolate: effect on cocoa butter 
digestibility and blood lipids in humans. Am J Clin Nutr 73, 246-252.

14. Reid IR (2004) Effects of calcium supplementation on circulating lipids: potential pharmacoeconomic implications. Drugs Aging 21, 7-17.

15. Reid IR, Mason B, Horne A, et al. (2002) Effects of calcium supplementation on serum lipid concentrations in normal older women: a randomized controlled trial. Am J Med 112, 343-347.

16. Bostick RM, Fosdick L, Grandits GA, et al. (2000) Effect of calcium supplementation on serum cholesterol and blood pressure. A randomized, double-blind, placebo-controlled, clinical trial. Arch Fam Med 9, 31-38.

17. Major GC, Alarie F, Doré J, et al. (2007) Supplementation with calcium + vitamin D enhances the beneficial effect of weight loss on plasma lipid and lipoprotein concentrations. Am J Clin Nutr 85, 54-59.

18. Karanja N, Morris CD, Rufolo P, et al. (1994) Impact of increasing calcium in the diet on nutrient consumption, plasma lipids, and lipoproteins in humans. Am J Clin Nutr 59, 900-907.

19. Lorenzen JK \& Astrup A (2011) Dairy calcium intake modifies responsiveness of fat metabolism and blood lipids to a high-fat diet. Br J Nutr 105, 1823-1831.

20. Andersen PE \& Just A (1983) Tabeller Over Foderstoffers Sammensatning m.m. Kvaeg-Svin. 8: Udgave (Tables of Feed Composition etc. for Cattle and Pigs). Copenhagen, Denmark: Landhusholdningsselskabets Forlag.

21. Cummings JH, Jenkins DJ \& Wiggins HS (1976) Measurement of the mean transit time of dietary residue through the human gut. Gut 17, 210-218.

22. Westerterp KR, Donkers JH, Fredrix EW, et al. (1995) Energy intake, physical activity and body weight: a simulation. $\mathrm{BrJ}$ Nutr 73, 337-347.

23. Nordic Nutrition Recommendations (2004) Integrating Nutrition and Physical Activity. Nord 2004:13. Copenhagen: Nordic Council of Ministers.

24. Bouchard C, Tremblay A, Leblanc C, et al. (1983) A method to assess energy expenditure in children and adults. $A m \mathrm{~J}$ Clin Nutr 37, 461-467.

25. Jensen SK (2008) Improved Bligh \& Dyer extraction procedure. Lipid Technol 20, 280-281.

26. Dekker R, Van der Meer R \& Olieman C (1991) Sensitive pulsed amperometric detection of free and conjugated bile acids in combination with gradient reversed-phase HPLC. Chromatographia 31, 549-553.

27. Knarreborg A, Engberg RM, Jensen SK, et al. (2002) Quantitative determination of bile salt hydrolase activity in bacteria isolated from the small intestine of chickens. Appl Environ Microbiol 68, 6425-6428.

28. Mensink RP, Zock PL, Kester AD, et al. (2003) Effects of dietary fatty acids and carbohydrates on the ratio of serum total to HDL cholesterol and on serum lipids and apolipoproteins: a meta-analysis of 60 controlled trials. Am J Clin Nutr 77, $1146-1155$.

29. Gacs G \& Barltrop D (1977) Significance of Ca-soap formation for calcium absorption in the rat. Gut 18, 64-68.

30. Govers MJ, Termont DS, Van Aken GA, et al. (1994) Characterization of the adsorption of conjugated and unconjugated bile acids to insoluble, amorphous calcium phosphate. J Lipid Res 35, 741-748.

31. Patton JS \& Carey MC (1979) Watching fat digestion. Science 204, 145-148.

32. van der Meer R \& De Vries HT (1985) Differential binding of glycine- and taurine-conjugated bile acids to insoluble calcium phosphate. Biochem J 229, 265-268.

33. Bhattacharyya AK, Thera C, Anderson JT, et al. (1969) Dietary calcium and fat. Effect on serum lipids and fecal excretion of cholesterol and its degradation products in man. Am J Clin Nutr 22, 1161-1174.

34. Bendsen NT, Hother AL, Jensen SK, et al. (2008) Effect of dairy calcium on fecal fat excretion: a randomized crossover trial. Int J Obes (Lond) 32, 1816-1824.

35. Ditscheid B, Keller S \& Jahreis G (2005) Cholesterol metabolism is affected by calcium phosphate supplementation in humans. J Nutr 135, 1678-1682.

36. Song Y, He K, Levitan EB, et al. (2006) Effects of oral magnesium supplementation on glycaemic control in type 2 diabetes: a meta-analysis of randomized double-blind controlled trials. Diabet Med 23, 1050-1056.

37. Gordon DJ, Probstfiels JL, Garrison RJ, et al. (1989) Highdensity lipoprotein cholesterol and cardiovascular disease four prospective American studies. Circulation 79, 8-15.

38. Bolland MJ, Avenell A, Baron JA, et al. (2010) Effect of calcium supplements on risk of myocardial infarction and cardiovascular events: meta-analysis. BMJ 29, 341.

39. Li K, Kaaks R, Linseisen J, et al. (2012) Associations of dietary calcium intake and calcium supplementation with myocardial infarction and stroke risk and overall cardiovascular mortality in the Heidelberg cohort of the European Prospective Investigation into Cancer and Nutrition study (EPIC-Heidelberg). Heart 98, 920-925.

40. Pedersen AN, Fagt S, Groth MV, et al. (2010) Danskernes kostvaner 2003-2008 (Dietary Habits in Denmark 2003-2008). Søborg, Denmark: Hovedresultater, Danmarks Fødevareforskning. 